\title{
Agreement between a simple dyspnea-guided treatment algorithm for stable COPD and the GOLD guidelines: a pilot study
}

This article was published in the following Dove Press journal:

International Journal of COPD

8 June 2016

Number of times this article has been viewed

Carlos Cabrera,' Ciro Casanova, ${ }^{2}$ Yolanda Martín, ${ }^{3}$ Virginia Mirabal, ${ }^{3}$ María del Carmen Sánchez, ${ }^{4}$ Felisa Álvarez, ${ }^{5}$ Gabriel Juliá,' Pedro Cabrera-Navarro,' Miguel Ángel García-Bello, ${ }^{6}$ José María Marín, ${ }^{7}$ Juan Pablo de-Torres, ${ }^{8}$ Miguel Divo, ${ }^{9}$ Bartolomé Celli ${ }^{9}$

'University Hospital of Gran Canaria Dr Negrín, Respiratory Service, Las Palmas de Gran Canaria, Spain; ${ }^{2}$ University Hospital Nuestra Señora de la Candelaria, Respiratory Service, Santa Cruz de Tenerife, Spain; ${ }^{3}$ Arucas Health Center, Primary Care Las Palmas de Gran Canaria, Spain; ${ }^{4}$ Cueva Torres Health Center, Primary Care Las Palmas de Gran Canaria, Spain; ${ }^{5}$ La Feria Health Center, Primary Care Las Palmas de Gran Canaria, Spain; ${ }^{6}$ University Hospital of Gran Canaria Dr Negrín, Investigation Unit, Las Palmas de Gran Canaria, Spain; ${ }^{7}$ University Hospital Miguel Servet, Respiratory Service, Zaragoza, Spain; ${ }^{8}$ Navarra University Clinic, Respiratory Service, Pamplona, Spain; ${ }^{9}$ Brigham and Women's Hospital, Pulmonary and Critical Care Service, Boston, MA, USA

Correspondence: Carlos Cabrera University Hospital of Gran Canaria Dr Negrín, Respiratory Service, la Ballena $\mathrm{S} / \mathrm{N}$, 35010 Las Palmas de Gran Canaria, Spain Email ccablopn@gmail.com
Introduction: Guidelines recommendations for the treatment of COPD are poorly followed. This could be related to the complexity of classification and treatment algorithms. The purpose of this study was to validate a simpler dyspnea-based treatment algorithm for inhaled pharmacotherapy in stable COPD, comparing its concordance with the current Global Initiative for Obstructive Lung Disease (GOLD) guideline.

Methods: We enrolled patients who had been diagnosed with COPD in three primary care facilities and two tertiary hospitals in Spain. We determined anthropometric data, forced expiratory volume in the 1st second (percent), exacerbations, and dyspnea based on the modified Medical Research Council scale. We evaluated the new algorithm based on dyspnea and exacerbations and calculated the concordance with the current GOLD recommendations.

Results: We enrolled 100 patients in primary care and 150 attending specialized care in a respiratory clinic. There were differences in the sample distribution between cohorts with $41 \%$ vs $26 \%$ in grade $\mathrm{A}, 16 \%$ vs $12 \%$ in grade $\mathrm{B}, 16 \%$ vs $22 \%$ in grade $\mathrm{C}$, and $27 \%$ vs $40 \%$ in grade $\mathrm{D}$ for primary and respiratory care, respectively $(P=0.005)$. The coincidence of the algorithm with the GOLD recommendations in primary care was $93 \%$ and $91.8 \%$ in the respiratory care cohort.

Conclusion: A simple dyspnea-based treatment algorithm for inhaled pharmacotherapy of COPD could be useful in the management of COPD patients and concurs very well with the recommended schema suggested by the GOLD initiative.

Keywords: COPD, treatment, algorithm, primary care

\section{Introduction}

COPD is associated with a high economic burden and is also one of the most important causes of morbidity and mortality worldwide. ${ }^{1,2}$ COPD has a high prevalence in the adult population, ${ }^{3-5}$ and most of the patients are usually treated in a primary care setting. However, several international studies have shown that the actual implementation of guidelines is very limited including the one published by the Global Initiative for Obstructive Lung Disease (GOLD). ${ }^{6}$ Pérez et al found that in the US just $12 \%$ of primary care physicians used the forced expiratory volume in the 1 st second $\left(\mathrm{FEV}_{1}\right)$ to guide their prescriptions, while Chávez et al showed how only $40 \%$ of patients had a treatment in agreement with the international recommendations. ${ }^{7,8}$ These data are similar to those shown in Denmark, Canada, Switzerland, or the People's Republic of China..$^{9-12}$ Moreover, only $18 \%$ of patients in Spain were being treated following the international standards. ${ }^{13}$

The reasons for the guidelines being poorly followed are not known, but the lack of real-time spirometry, incorporation of several symptoms scales of different dimension 
and the complexity in treatment algorithms are common hindrances to follow international recommendations in clinical practice. Recognizing these limitations and being faced with the fact that the most important complaint that drives patients to seek medical attention is the presence of dyspnea, first the Canadian COPD guidelines and more recently Agustí and Fabbri have proposed a simple symptom-driven treatment algorithm, but its validity has not been properly tested. ${ }^{14,15}$

We hypothesized that this simple symptom-driven treatment algorithm could indeed be validated in the primary and secondary care settings. To test the hypothesis, we implemented a dyspnea-based algorithm in two separate cohorts, and the use of the algorithm was then objectively compared with the current GOLD guidelines to inform its concordance and provide external validity.

\section{Methods}

We conducted a cross-sectional study in two cohorts - one consisted of three primary care facilities and the other consisted of two specialized consultation clinics (tertiary hospitals in Spain). In the primary care cohort, we collected the data of all patients with a coded COPD diagnosis who were under the care of nine primary care physicians between September 2014 and January 2015. The specialty care cohort consisted of outpatients derived by primary care for specialized attention between 2012 and 2015. COPD patients in each specialized consultation were selected consecutively.

In both study cohorts, we determined anthropometric data (age, sex, and BMI, calculated as weight in kilograms divided by the square of height in meters). The $\mathrm{FEV}_{1} \%$ predicted and absolute were measured using American Thoracic Society/ European Respiratory Society (ATS/ERS) standards. ${ }^{16}$
Exacerbations were defined as any episode of worsening of dyspnea, cough, or sputum requiring antibiotics or systemic corticosteroids or admission to the hospital due to COPD exacerbation. The intensity of dyspnea was evaluated by the modified Medical Research Council scale (mMRC). ${ }^{17}$ The common inclusion criteria for both cohorts included being at least 40 years old, having a history of smoking (packyear $>10$ ), and being able to perform spirometry properly. All the patients had to be in stable condition for at least 6 weeks, including all comorbidities with possible interference with dyspnea evaluation, and receiving optimal medical therapy from either the primary or specialized physician criteria. COPD was defined by a post-bronchodilator $(400 \mu \mathrm{g}$ of albuterol) spirometry showing an $\mathrm{FEV}_{1} /$ forced vital capacity $(\mathrm{FVC})<0.7^{18}$ and $\mathrm{FEV}_{1}$ lower than $80 \%$ predicted using standard predictive equations in Spain. ${ }^{19}$ All participants signed the informed consent, and the study was approved by the ethics committees of both the University Hospital of Gran Canaria Dr Negrín and the University Hospital Nuestra Señora de la Candelaria.

\section{Treatment algorithm}

The algorithm was based on dyspnea and exacerbations as proposed by the Canadian guidelines and others ${ }^{14,15}$ (Figure 1). Patients were divided according to the dyspnea score, measured by the mMRC scale, into a high- or a low-dyspnea score group. If the patient had a low dyspnea score ( $\leq 1$ using the mMRC dyspnea scale), one long-acting bronchodilator was given. Two bronchodilators were given from the beginning if the patient had a high dyspnea score ( $\geq 2$ mMRC dyspnea scale). If there were $\geq 2$ exacerbations in the previous year, inhaled corticosteroids were added to

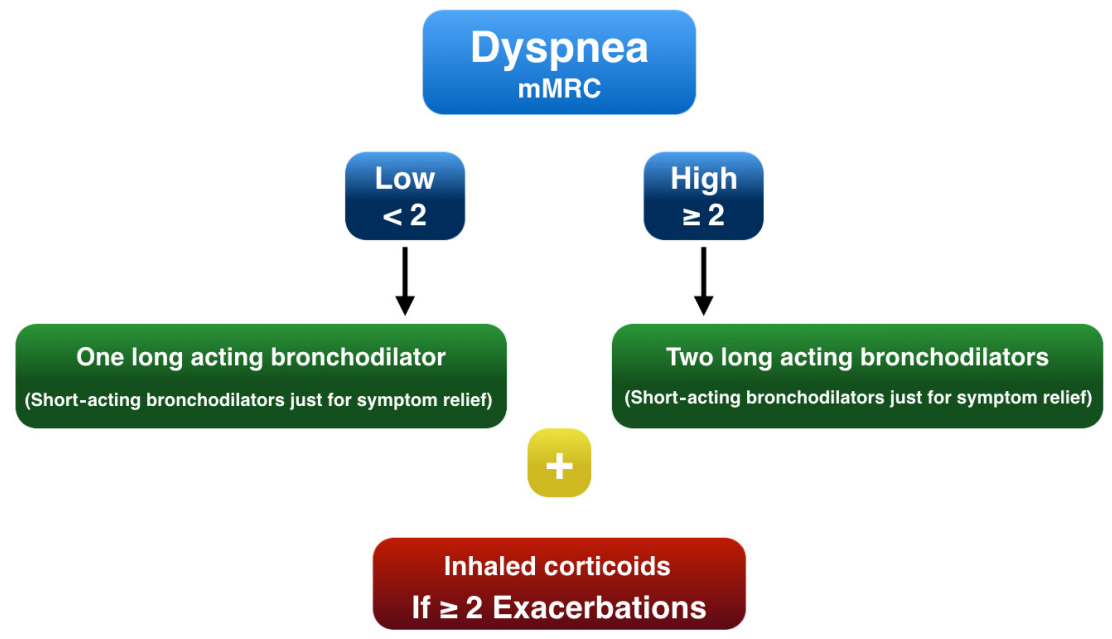

Figure I Proposed treatment algorithm.

Abbreviation: mMRC, Modified Medical Research Council scale. 
the treatment, independently of the dyspnea degree. Shortacting bronchodilators were given only for symptom relief.

\section{Validation with the 20 II GOLD recommendations}

All patients were classified by both the GOLD criteria (using the mMRC score to measure dyspnea) and by the proposed algorithm. Treatment was estimated for both options and the degree of coincidence was calculated as a percentage. Coincidence with the GOLD recommendations was achieved if the therapy proposed matched one of the suggestions given by the GOLD document (first or second choice indistinctly). Non-coincidence was achieved when no agreement with the GOLD recommendations was found. Possible coincidence was achieved if one of the GOLD recommendations was included in the options provided by the tested algorithm.

\section{Statistical analysis}

The sample size was calculated assuming a rate of coincidence close to $90 \%$ for each one of the cohorts considered. A sample size of 96 patients per cohort would estimate the aforementioned rates with an error bound of $6 \%$ and a confidence level of $95 \%$.

Categorical variables were expressed as frequencies and percentages, and continuous variables as mean and standard deviation (SD). The percentages were compared using the chi-square $\left(\chi^{2}\right)$ test or the linear association test and the means by the Student's $t$-test. The rates of coincidence were estimated by means of $95 \%$ confidence intervals (CI) using the bootstrap methods. Kappa index and similar equations cannot be used in this setting due to the multiple treatment choices contained in each GOLD grade. The statistical significance was set at $P<0.05$. Analyses were performed with the R package binGroup. ${ }^{20}$

\section{Results}

All the patients in the primary care $(\mathrm{n}=100)$ and respiratory cohort $(n=150)$ had spirometrically defined COPD confirmed using the GOLD or the lower limit of normal criteria. The characteristics of the sample are shown in Table 1. The severity distribution by GOLD grades was different between the primary care and the specialized cohorts, being more severe in the specialized one $(P<0.005)$. The perception of dyspnea was lower in patients with higher $\mathrm{FEV}_{1}$ (percent predicted) and higher in patients with the lowest values. Indeed, the average $\mathrm{FEV}_{1}$ value was $70.8 \%$ in patients with the lowest score in the mMRC scale and $35 \%$ in those with the highest score $(P<0.001)$.
Table I Main characteristics of the primary and specialized care cohorts

\begin{tabular}{llll}
\hline & $\begin{array}{l}\text { Primary } \\
\text { care cohort } \\
\text { N=100 }\end{array}$ & $\begin{array}{l}\text { Respiratory } \\
\text { care cohort } \\
\mathbf{N}=150\end{array}$ & P-value \\
\hline Age, years & $65.6 \pm 10.6$ & $61.8 \pm 9.7$ & 0.004 \\
Male/female, \% & $67.0 / 33.0$ & $57.5 / 42.5$ & 0.134 \\
BMI & $26.86 \pm 5.2$ I & $26.53 \pm 4.97$ & 0.600 \\
FEV $\%$ & $66.6 \pm 22.7$ & $57.4 \pm 20.5$ & 0.00 I \\
Exacerbations & & & $0.464^{*}$ \\
None & $46(46.0)$ & $68(45.3)$ & \\
$\quad$ I & $22(22.0)$ & $27(18.0)$ & \\
2 & $17(17.0)$ & $24(16.0)$ & \\
$\geq 3$ & $15(15.0)$ & $31(20.7)$ & 0.163 \\
mMRC $\geq 2$ & $43(43.0)$ & $78(52.0)$ & $0.005^{*}$ \\
GOLD grade & & & \\
A & $41(41.0)$ & $39(26.0)$ & \\
B & $16(16.0)$ & $18(12.0)$ & \\
C & $16(16.0)$ & $35(22.0)$ & \\
D & $27(27.0)$ & $60(39.9)$ & \\
\hline
\end{tabular}

Notes: Data are shown as mean \pm SD and frequencies (\%); *linear association test. Abbreviations: GOLD, Global Initiative for Obstructive Lung Disease; mMRC, modified Medical Research Council scale; SD, standard deviation.

In the primary care cohort, the distribution of patients by GOLD grades was as follows: $\mathrm{A}=41 \%, \mathrm{~B}=16 \%, \mathrm{C}=16 \%$, and $\mathrm{D}=27 \%$. The correspondence of the proposed algorithm with the GOLD treatment recommendations in the primary care cohort was $93 \%(95 \% \mathrm{CI}=88.0 \%-98.0 \%)$, while $7 \%$ had possible coincidence. This group was limited to GOLD grade $\mathrm{C} 1\left(<2\right.$ exacerbations and $\left.\mathrm{FEV}_{1} \%<50 \%\right)$ which accounted for $43.7 \%$ of grade $\mathrm{C}$ (Table 2). However, the proportion of patients that actually followed the GOLD treatment recommendations was $36 \%$. The agreement in grade A was $23 \%$, while in grades B, C, and D was $36 \%, 23 \%$, and $62 \%$ respectively. The proportion of patients treated with inhaled corticosteroids was $47 \%$ in the primary care cohort, being $41 \%$ in grade $\mathrm{A}, 12 \%$ in $\mathrm{B}, 10 \%$ in $\mathrm{C}$, and $62 \%$ in $\mathrm{D}$. There were no differences with the hospital cohort in the mean number of exacerbations in the previous year or in the mMRC scale.

In the respiratory care cohort, the distribution of patients by GOLD grades was as follows: $26 \%$ in grade A and

Table 2 Rate of coincidence of the new algorithm with current GOLD recommendations (primary care, respiratory care, and both cohorts together)

\begin{tabular}{|c|c|c|c|}
\hline & \multicolumn{2}{|l|}{ Cohort } & \multirow[t]{2}{*}{ Tota } \\
\hline & Primary & Respiratory & \\
\hline \multicolumn{4}{|c|}{ Coincidence } \\
\hline $\mathrm{n}$ & 93 & 137 & 228 \\
\hline$\%$ & 93.0 & 91.8 & 92.3 \\
\hline \multicolumn{4}{|c|}{ Possible coincidence } \\
\hline $\mathrm{n}$ & 7 & 13 & 19 \\
\hline$\%$ & 7.0 & 8.2 & 7.7 \\
\hline \multicolumn{4}{|l|}{ Total } \\
\hline $\mathrm{n}$ & 100 & 150 & 250 \\
\hline
\end{tabular}

Abbreviation: GOLD, Global Initiative for Obstructive Lung Disease. 


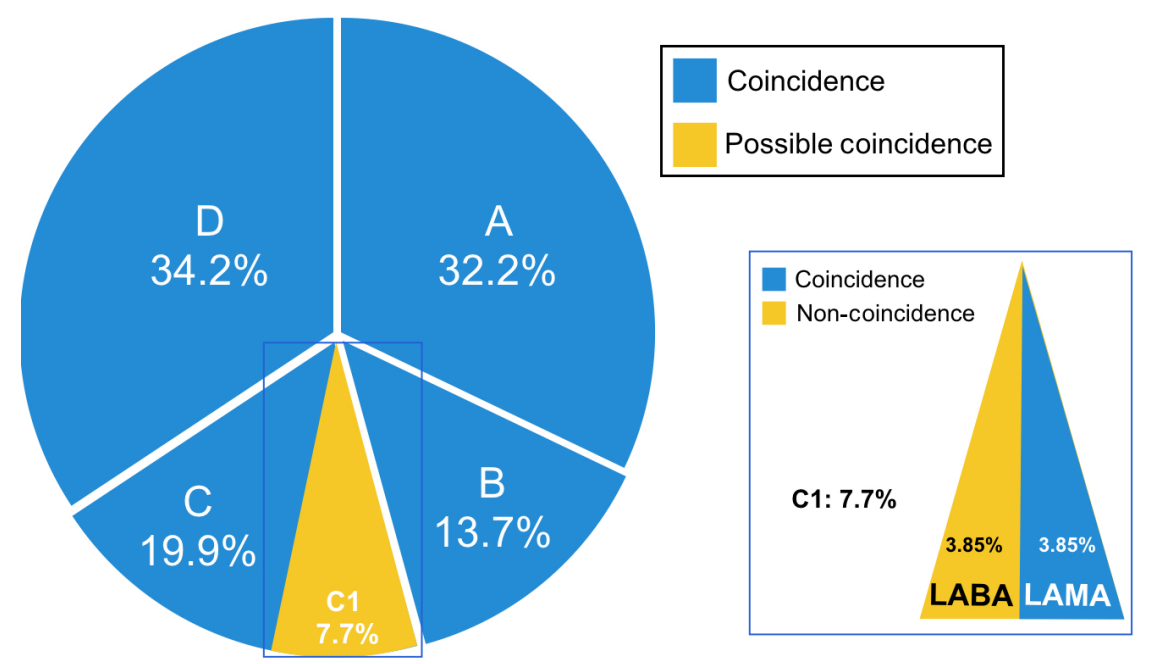

Figure 2 Whole sample distribution by GOLD grades.

Note: Colors show coincidence, possible coincidence, or non-coincidence in the whole cohort.

Abbreviations: GOLD, Global Initiative for Obstructive Lung Disease; LABA, long-acting beta adrenergic; LAMA, long-acting anticholinergic.

$12 \%, 22 \%$, and $40 \%$ in grades $\mathrm{B}, \mathrm{C}$, and $\mathrm{D}$, respectively. The correspondence of the proposed algorithm with the GOLD recommendations in this sample was $91.8 \%(95 \%$ $\mathrm{CI}=87.8 \%-96.6 \%$ ), while $8.2 \%$ had possible coincidence. This group was also limited to GOLD grade $\mathrm{C} 1$. The proportion of patients that actually followed the GOLD treatment recommendations was $63 \%$. The agreement in grade $\mathrm{A}$ was $31 \%$, while in grades B, C, and D it was $52 \%, 71 \%$, and $63 \%$ respectively. The proportion of patients treated with inhaled corticosteroids was $37 \%$ in the specialized cohort, being $24 \%$ in grade $\mathrm{A}, 35 \%$ in $\mathrm{B}, 33 \%$ in $\mathrm{C}$ and $56 \%$ in $\mathrm{D}$.

When the algorithm proposed was assessed by means of $\mathrm{FEV}_{1} \%$ in the whole cohort, we found a $100 \%$ concordance in subjects with $\mathrm{FEV}_{1} \%>50 \%$, while $18.8 \%$ of subjects with $\mathrm{FEV}_{1} \%<50 \%$ had possible coincidence. The correspondence of the algorithm with the GOLD recommendations in the whole sample $(\mathrm{n}=250)$ was $92.3 \%(95 \% \mathrm{CI}=89.1 \%-95.6 \%)$, while $7.7 \%$ had possible coincidence (Figure 2).

\section{Discussion}

This study shows that once the diagnosis of COPD has been spirometrically confirmed, a simplified dyspnea-based inhaled treatment algorithm has an excellent $(92.3 \%)$ concordance in the primary and specialty outpatient clinics outlined within the 2011 GOLD recommendations. We believe this simple algorithm could help improve acceptance by busy clinicians.

The implementation of COPD guidelines independently of location is very limited, and given the wide presence and large burden of disease, the need to improve the quality on COPD treatment in any setting would be advisable. There have been some proposals that have attempted to simplify the treatment algorithm of COPD, anchoring its approach on the grading of dyspnea, the most important symptom affecting patients with COPD and the one that has important prognostic implications. ${ }^{14,15}$ The Canadian COPD guidelines have centered their therapy on increasing symptoms, ${ }^{15}$ while Agustí and Fabbri ${ }^{14}$ have published a simplified algorithm that coincides in principle with the Canadian approach. Validation of this approach could provide an easier way to direct patient treatment and could help health care providers to avoid confusion surrounding COPD treatment, and thus help achieve a better and more rational therapy. By improving treatment accuracy, this approach could also contribute to save resources, as it has been shown that providing an appropriate treatment to COPD patients who may be receiving wrong prescriptions might save $\sim 700$ euros per year. ${ }^{13}$ In 2011, the GOLD committee suggested a new non-evidencebased grading schema that aims to direct therapy and has become the desirable standard for COPD pharmacotherapy guidance. The most important finding in this study is the high concordance between this simple dyspnea-driven algorithm and the GOLD guidelines both in the primary and in the specialty care settings. An algorithm based on dyspnea is simple and easy to understand, primarily because it is based on the most frequent symptom for which patients seek medical consultation. In addition, accepted scales, like the mMRC scale, very much resemble the widely used New York Heart Association functional classification of heart failure that has also been shown to be an important prognostic tool for patients with COPD. The relevance of dyspnea as the main prognosis symptom is supported by the studies of Nishimura et $\mathrm{a}^{21}$ and Almagro et al, ${ }^{22}$ while Celli et $\mathrm{a}^{23}$ included dyspnea 
in the BODE index, proving itself as one of the best predictors in the index. ${ }^{23}$

This treatment algorithm lacks pulmonary function tests as a mandatory way to follow the effect of initial therapy. Neither the GOLD document nor other COPD guidelines have reached a consensus yet regarding the necessary or appropriate time to perform a spirometry in a stable patient. In fact, Casanova et $\mathrm{al}^{24}$ have recently shown that the $\mathrm{FEV}_{1} \%$ change over time did not relate directly to mortality. ${ }^{24}$ However, a spirometry may help determine the degree of objective response, and until more data are available, we may need to depend on the clinician judgment. On the other hand, by not performing sequential spirometry, we probably avoid a practical problem in busy clinical settings. There are several reasons why pulmonary function tests are not carried out as they should be, such as the lack of spirometer or qualified staff to perform the technique and also lack of knowledge about interpretation of the results. We believe that clinical decisions in daily practice are made based on symptoms rather than on function tests. Without spirometry, we have observed a $92.3 \%$ correspondence with the treatment proposed by the GOLD document, so the combination of exacerbations and symptoms are probably as useful as $\mathrm{FEV}_{1} \%$ in clinical daily practice, allowing us to exclude the $\mathrm{FEV}_{1}$ from the algorithm of the initial treatment approach for COPD. The lack of spirometry in this proposal does not mean that pulmonary function tests are not worthy. Spirometry is an essential tool to diagnose COPD and to exclude other potential causes of dyspnea not due to COPD, such as asthma, interstitial lung disease with restrictive physiology, and even cardiac problems where the spirometry may be normal. It also characterizes COPD patients better, and its performance over 2 years in order to determine disease progression has been proven, even in a clinically stable disease. ${ }^{25}$ Obviously, in patients with worsening symptoms, spirometry must be performed, as patients with a rapid decline have a worse overall prognosis. ${ }^{26}$ Finally, we believe that the current algorithm can serve as the basis for the evaluation of added spirometry with outcomes as the yardstick to determine its utility.

In the dyspnea-driven algorithm, the use of short bronchodilators as main therapy has been avoided and has been recommended just for symptom relief. COPD is a chronic disease and the evidence provided by every study where long-acting versus short-acting bronchodilators have been compared, indicates superiority not only in lung function but also in patient-related outcomes. ${ }^{27,28}$ Moreover, the frequency of administration, the lack of strength compared with longacting drugs, and the probable progression of the disease led us to exclude these medications as main therapy for COPD.
We think this decision helps minimize errors in treatment by reducing confusion in busy clinical practice.

We are aware that this algorithm has some limitations as well. First, we do not have a $100 \%$ concordance with the GOLD document. This discordance is located in patients in grade $\mathrm{C} 1$ ( $<2$ exacerbations and a $\mathrm{FEV}_{1} \%<50 \%$ ). Giving long-acting anticholinergic (LAMA) matches one of the choices proposed by GOLD, but giving long-acting beta adrenergic (LABA) is not contemplated in GOLD recommendations. We are acquainted with the fact LAMAs have more evidence than LABAs, but the maintenance of both options keeps the algorithm simple and easier to apply. Drugs like indacaterol, vilanterol, or olodaterol have a similar degree of bronchodilation as tiotropium and reduce exacerbations in almost the same proportion, so they could be considered appropriate alternative choices. In addition, grade $\mathrm{C}$ is the less populated group in the GOLD classification in several studies, thereby minimizing this discrepancy that overall remains very small. ${ }^{29}$ Another potential limitation is the use of a categorical scale such as mMRC to measure dyspnea. Dyspnea is a continuum and as such it is not biologically precise when measured in five steps. Dyspnea scales also need to be used with caution, as comorbidities must necessarily be ruled out in order to measure just COPD breathlessness. However, the mMRC scale is simple, and it resembles the New York Heart Association scale of functional disability, which has great diffusion and acceptance among primary care doctors, and very importantly, it is an excellent mortality predictor in COPD.

In this study, we left out drugs like roflumilast, theophyline, antibiotics, and other treatment options like oxygen, rehabilitation, or volume reduction because a patient who is not well controlled with the powerful inhaled medications available in regular care would be best served by a consultation with a specialist in COPD who can then address the potential use of these therapies.

A question that could be raised is what would happen when a patient with low dyspnea score has no improvement with one long-acting bronchodilator. We think that, after excluding other causes of dyspnea, another long-acting bronchodilator should be added. This will be a logical step up in the treatment algorithm. Since this dyspnea-based algorithm is meant to be used in clinical practice, we have defined improvement as having a decrease of at least one step in the mMRC scale. This longitudinal approach should be validated in the future in a prospective study.

\section{Conclusion}

In summary, we have explored and validated the implementation of a simple, practical algorithm for inhaled 
pharmacotherapy in stable COPD that centers on the symptom of dyspnea and the presence of exacerbations. This algorithm has a $92.3 \%$ agreement with the current GOLD recommendations in the primary and specialty setting. This approach could help busy providers to implement good pharmacological care for COPD treatment in clinical practice.

\section{Disclosure}

The authors report no conflicts of interest in this work.

\section{References}

1. European Respiratory Society. European Lung White Book. Huddersfield: European Respiratory Society Journals, Ltd; 2003.

2. Mathers CD, Loncar D. Projections of global mortality and burden of disease from 2002 to 2030. PLoS Med. 2006;3:e442.

3. Buist AS, McBurnie MA, Vollmer WM, et al. International variation in the prevalence of COPD (the BOLD study): a population-based prevalence study. Lancet. 2007;370:741-750.

4. Cabrera Lopez C, Julia Serda G, Cabrera Lacalzada C, et al. Prevalence of chronic obstructive pulmonary disease in the Canary Islands. Arch Bronconeumol. 2014;50:272-277.

5. Miravitlles M, Soriano JB, Garcia-Rio F, et al. Prevalence of COPD in Spain: impact of undiagnosed COPD on quality of life and daily life activities. Thorax. 2009;64:863-868.

6. The Global Strategy for the Diagnosis MAPOCOPD, Global Initiative for Chronic Obstructive Lung Disease (GOLD) 2015. Available from: http://www.goldcopd.org/. Accessed April 14, 2016.

7. Chavez PC, Shokar NK. Diagnosis and management of chronic obstructive pulmonary disease (COPD) in a primary care clinic. COPD. 2009;6:446-451.

8. Perez X, Wisnivesky JP, Lurslurchachai L, et al. Barriers to adherence to COPD guidelines among primary care providers. Respir Med. 2012;106:374-381.

9. Bourbeau J, Sebaldt RJ, Day A, et al. Practice patterns in the management of chronic obstructive pulmonary disease in primary practice: the CAGE study. Can Respir J. 2008;15:13-19.

10. Lange P, Rasmussen FV, Borgeskov H, et al. The quality of COPD care in general practice in Denmark: the KVASIMODO study. Prim Care Respir J. 2007;16:174-181.

11. Li F, Cai Y, Zhu Y, et al. The evaluation of general practitioners' awareness/knowledge and adherence to the GOLD guidelines in a Shanghai Suburb. Asia Pac J Public Health. 2015;27(2):NP2067-NP2078.

12. Rutschmann OT, Janssens J-P, Vermeulen B, et al. Knowledge of guidelines for the management of COPD: a survey of primary care physicians. Respir Med. 2004;98:932-937.

13. Miravitlles M, Sicras A, Crespo C, et al. Costs of chronic obstructive pulmonary disease in relation to compliance with guidelines: a study in the primary care setting. Ther Adv Respir Dis. 2013;7:139-150.

14. Agusti A, Fabbri LM. Inhaled steroids in COPD: when should they be used? Lancet Respir Med. 2014;2:869-871.
15. ODonnell DE, Hernandez P, Kaplan A, et al. Canadian Thoracic Society recommendations for management of chronic obstructive pulmonary disease - 2008 update - highlights for primary care. Can Respir J. 2008; 15:1A.

16. Celli BR, MacNee W, Agusti A, et al. Standards for the diagnosis and treatment of patients with COPD: a summary of the ATS/ERS position paper. Eur Respir J. 2004;23:932.

17. Bestall JC, Paul EA, Garrod R, et al. Usefulness of the Medical Research Council (MRC) dyspnoea scale as a measure of disability in patients with chronic obstructive pulmonary disease. Thorax. 1999;54: 581-586.

18. Miller MR, Hankinson J, Brusasco V, et al. Standardisation of spirometry. Eur Respir J. 2005;26:319-338.

19. Castellsagué J, Burgos F, Sunyer J, et al. Prediction equations for forced spirometry from European origin populations. Barcelona Collaborative Group on Reference Values for Pulmonary Function Testing and the Spanish Group of the European Community Respiratory Health Survey. Respir Med. 1998;92:401-407.

20. Bilder CR, Zhang B, Schaarschmidt F, et al. binGroup: a package for group testing. $R J .2010 ; 2: 56-60$.

21. Nishimura K, Izumi T, Tsukino M, et al. Dyspnea is a better predictor of 5 -year survival than airway obstruction in patients with COPD. Chest. 2002;121:1434-1440.

22. Almagro P, Martinez-Camblor P, Soriano JB, et al. Finding the best thresholds of FEV1 and dyspnea to predict 5-year survival in COPD patients: the COCOMICS study. PLoS One. 2014;9:e89866.

23. Celli BR, Cote CG, Marin JM, et al. The body-mass index, airflow obstruction, dyspnea, and exercise capacity index in chronic obstructive pulmonary disease. $N$ Engl J Med. 2004;350:1005.

24. Casanova C, Aguirre-Jaime A, de Torres JP, et al. Longitudinal assessment in COPD patients: multidimensional variability and outcomes. Eur Respir J. 2014;43:745-753.

25. Casanova C, de Torres JP, Aguirre-Jaime A, et al. The progression of chronic obstructive pulmonary disease is heterogeneous: the experience of the BODE cohort. Am J Respir Crit Care Med. 2011;184: $1015-1021$.

26. Lange P, Celli B, Agustí A, et al. Lung-function trajectories leading to chronic obstructive pulmonary disease. $N$ Engl J Med. 2015;373: $111-122$.

27. D'Urzo AD, De Salvo MC, Ramirez-Rivera A, et al. In patients with $\mathrm{COPD}$, treatment with a combination of formoterol and ipratropium is more effective than a combination of salbutamol and ipratropium: a 3-week, randomized, double-blind, within-patient, multicenter study. Chest. 2001;119:1347-1356.

28. van Noord JA, Aumann JL, Janssens E, et al. Comparison of tiotropium once daily, formoterol twice daily and both combined once daily in patients with COPD. Eur Respir J. 2005;26:214-222.

29. Lange P, Marott JL, Vestbo J, et al. Prediction of the clinical course of chronic obstructive pulmonary disease, using the new GOLD classification: a study of the general population. Am J Respir Crit Care Med. 2012; 186:975-981.
International Journal of COPD

\section{Publish your work in this journal}

The International Journal of COPD is an international, peer-reviewed journal of therapeutics and pharmacology focusing on concise rapid reporting of clinical studies and reviews in COPD. Special focus is given to the pathophysiological processes underlying the disease, intervention programs, patient focused education, and self management protocols.

\section{Dovepress}

This journal is indexed on PubMed Central, MedLine and CAS. The manuscript management system is completely online and includes a very quick and fair peer-review system, which is all easy to use. Visit $\mathrm{http}: / / \mathrm{www}$.dovepress.com/testimonials.php to read real quotes from published authors. 